\title{
Effectiveness and safety of morphine sulfate extended-release capsules in patients with chronic, moderate-to-severe pain in a primary care setting
}

\author{
This article was published in the following Dove Press journal: \\ Journal of Pain Research \\ 7 November 2011 \\ Number of times this article has been viewed
}

\section{James Brown' \\ Beatrice Setnik ${ }^{2}$ \\ Keung Lee ${ }^{3}$ \\ Jody M Cleveland ${ }^{2}$ \\ Carl L Roland ${ }^{2}$ \\ Linda Wase ${ }^{4}$ \\ Lynn Webster ${ }^{5}$}

'Jena Medical, Ormond Beach, FL; ${ }^{2}$ Pfizer Inc, Cary, NC; ${ }^{3}$ Randolph Medical Associates, Asheboro, NC; ${ }^{4}$ Archimedes Pharma US Inc, Bedminster, NJ; ${ }^{5}$ Lifetree Clinical Research, Salt Lake City, UT, USA
Correspondence: Beatrice Setnik Pfizer Inc, 4000 Centre Green Way Suite 300, Cary, NC 275I3, USA

$\mathrm{Tel}+19196537071$

Fax + I 9196537022

Email beatrice.setnik@pfizer.com
Background: The purpose of this study was to determine the effectiveness and safety of morphine sulfate extended-release capsules among primary care patients with chronic, moderateto-severe pain using a universal precautions approach that assessed and monitored risk for opioid misuse and abuse.

Methods: This open-label, uncontrolled, multicenter, prospective study was conducted in primary care centers $(n=281)$ and included opioid-naïve and opioid-experienced patients with either a pain score $\geq 4$ ( $0=$ no pain, $10=$ pain as bad as you can imagine), or with unacceptable side effects while taking opioids. The patients were treated with morphine sulfate extendedrelease capsules for up to four months. Patient-rated pain intensity (worst, least, average) over the past 24 hours $(0-10$ scale), pain interference with seven activities of daily living $(0=$ no interference, 10 = completely interferes), and adverse events were recorded.

Results: Of 1487 patients who filled at least one prescription, 561 (38\%) completed the study. Patients were primarily white (87\%) and female (57\%); $92 \%$ had pain for more than one year; and $79 \%$ were opioid-experienced. Median age was 52 years. Decreases in mean ( \pm standard deviation) average pain scores (baseline $6.2 \pm 2.3$ ) were $-0.8 \pm 2.2$ at visit 2 (5-14 days later), and $-1.6 \pm 2.3$ and $-1.7 \pm 2.2$ at visits 3 and 4 (spaced 3-4 weeks apart), respectively, and $-1.1 \pm 2.4$ at visit 5 (included patients withdrawn from the study who were no longer taking the study drug). A similar trend was observed for worst pain and least pain scores and for pain interference with activities. Fifty-one percent of the safety population patients and $81 \%$ in the completer population reported being satisfied or very satisfied with the study treatment. Most common adverse events were typical of opioids, ie, constipation (14\%), nausea (11\%), vomiting (5\%), and somnolence (5\%).

Conclusion: The results suggest that pain outcomes improved in patients with chronic, moderate-to-severe pain receiving morphine sulfate extended-release capsules within the context of a structured universal precautions approach in the primary care setting.

Keywords: opioids, analgesics, primary care, pain assessment, substance abuse, universal precautions

\section{Introduction}

One of the challenges associated with using opioid therapy for pain management is achieving benefit in an environment in which the misuse, abuse, and diversion of prescription pain medications have become nearly as common as use of illicit drugs. ${ }^{1-3}$ Before therapy is initiated, all patients under consideration for management 
with opioids should receive a thorough diagnostic workup and evaluation, and careful assessment of risk for opioid abuse. $^{4,5}$ Treatment goals should be established during patient-physician discussions. ${ }^{4}$ Guidelines recommend stratification of patients according to potential risk of aberrant behavior to aid in the choice of appropriate management and intervention., ${ }^{46}$ Gourlay et al have suggested using a "universal precautions" approach, modeled after that for infectious disease, whereby an appropriate minimum level of precaution is applied to all patients. ${ }^{6}$ Such an approach for pain management assumes all patients considered for opioid therapy should be screened for potential opioid or other drug misuse/abuse. Once opioid therapy has been initiated, all patients should be carefully monitored, with interventions based on their underlying risk factors and any emergent issues. ${ }^{4,6}$

Primary care providers are the largest single group of opioid prescribers in the United States. ${ }^{7}$ In general, primary care providers are the first to see patients with acute and chronic pain. ${ }^{8} 9$ However, there are few published studies on opioid misuse and abuse among patients on long-term opioid therapy for the management of chronic, moderate-to-severe pain in a primary care setting. ${ }^{10,11}$ Providers who have little specific training in pain medicine or addiction may be faced with providing pain management while managing the risks of misuse, abuse, and diversion associated with opioid analgesics. $^{8,9,12,13}$

There are no large-scale studies to date assessing the effectiveness of opioids in pain management (eg, control of pain and/or improvement of function at tolerable doses) while employing a universal precautions approach in the primary care setting. The current multicenter, uncontrolled, openlabel study, ${ }^{14}$ conducted in the primary care setting among a broad geographically distributed population, evaluated the effectiveness and tolerability of morphine sulfate extendedrelease capsules (Avinza ${ }^{\circledR}$, King Pharmaceuticals Inc, Bristol, TN, acquired by Pfizer Inc in March 2011) in patients with chronic, moderate-to-severe pain. ${ }^{15}$ Effectiveness, an evaluation of treatment under real-world conditions, ${ }^{16,17}$ was based on pain and functional assessments. This study was also designed to assess risk of opioid misuse and abuse, and the utility of a universal precautions approach in the primary care setting.

The universal precautions approach in this study included evaluation, documentation, and monitoring for potential risk of opioid misuse and abuse during treatment, intervention when aberrant drug-related behaviors were identified, and regular assessments to ensure that pain management goals were being met. ${ }^{6}$ Morphine sulfate extended-release, which contains both immediate-release and extended-release beads of morphine sulfate, is intended for once-daily administration for the relief of moderate-to-severe pain requiring aroundthe-clock opioid therapy for an extended period of time. ${ }^{15}$

The primary study objectives were to evaluate the effectiveness and safety of morphine sulfate extendedrelease in a primary care setting, assess the potential risk of misuse and abuse, and monitor aberrant behaviors and interventions among patients receiving the study drug. Secondary objectives were to determine the level of compliance using a universal precautions approach to chronic pain management during the study and after study completion, and to evaluate the activities of daily living of patients on chronic opioid therapy with morphine sulfate extended-release.

This paper focuses on the effectiveness and safety of morphine sulfate extended-release and the impact of chronic pain management on activities of daily living when pain was managed using a universal precautions approach to assess and monitor pain and risk of opioid abuse; a separate paper will report the results for risk of misuse and abuse and level of compliance in this study.

\section{Methods}

Before study initiation, the protocol and informed consent form were approved by an independent central institutional review board. All patients provided signed informed consent before beginning screening/baseline procedures. The investigator was responsible for ensuring that the study was conducted in accordance with the protocol, current International Conference on Harmonisation of Technical Requirements for Registration of Pharmaceuticals for Human Use Guidelines on Good Clinical Practice, and regulatory requirements. Study centers were selected from a nationally representative list of primary care physicians with experience in prescribing opioids. Investigators were questioned about their ability to complete the study requirements, and their credentials with respect to the Drug Enforcement Administration were verified. Investigators involved in the study participated in a 1.5-hour training program conducted live or via Webcast that reviewed procedures to be used and counseling to be provided to the patients. Those investigators who completed the training also received an hour-long instructional DVD on study procedures that they could review as needed during the study. 


\section{Patients}

Patients were adults (aged $\geq 21$ years) who had chronic, moderate-to-severe pain for at least three months prior to study entry. They could be opioid-naïve with a pain score $\geq 4$ on an 11-point numerical rating scale $(0=$ no pain, $10=$ pain as bad as you can imagine) or opioid-experienced but with suboptimal response (numerical rating scale pain score $\geq 4$ or unacceptable side effects). Patients were required to be able to read and understand English and comply with protocol requirements.

Main exclusion criteria were hypersensitivity to morphine, morphine salts, or any components of morphine sulfate extended-release, respiratory depression, acute or severe bronchial asthma or severe chronic obstructive pulmonary disease, currently taking morphine sulfate extended-release or would have required a dose of $>1600 \mathrm{mg} /$ day, pregnancy or breast-feeding, residing in a hospital or nursing home, or life expectancy less than two months. Patients could not have had more than two surgeries for lower back pain, or be required to undergo surgery or steroid injections for chronic pain over the next 12 weeks.

\section{Study design}

This was an open-label, nonrandomized, uncontrolled, multicenter study that included three periods, ie, screening/ baseline, treatment, and end of study (Figure 1). During each visit, patients underwent a series of evaluations to assess the effectiveness and safety of morphine sulfate extended-release

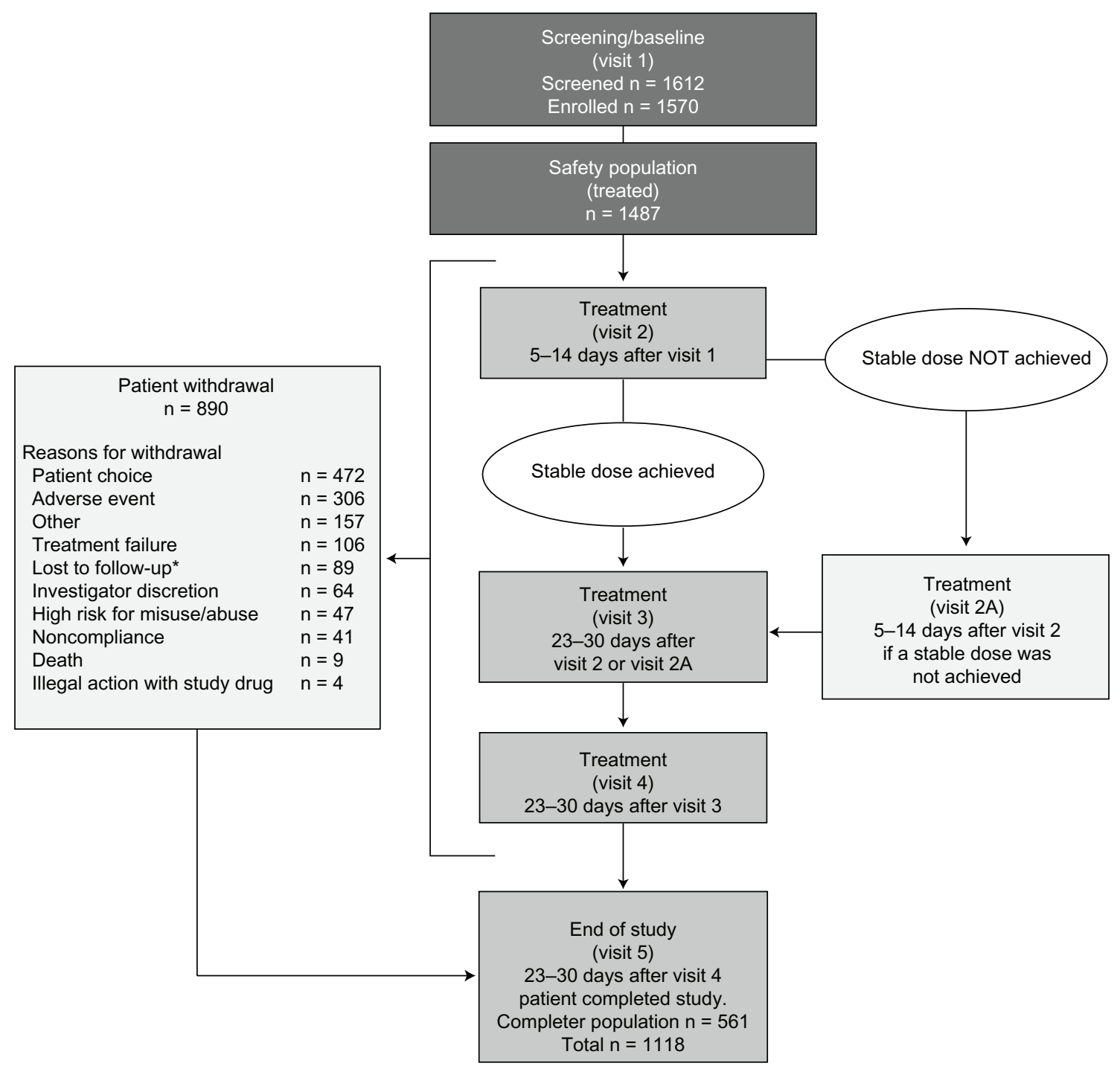

Figure I Study design.

Notes: *One patient categorized as "lost to follow-up" upon study termination was later identified as having died due to renal failure. 
and compliance under the universal precautions approach, to identify aberrant drug use, and to determine level of risk for misuse and abuse. At end of study and post-study, investigators completed assessments to determine their use of risk assessment tools and the universal precautions approach to pain management. Pain-related assessments will be discussed here; assessments of drug behavior and risk for misuse and abuse will be described in more detail in a separate paper.

Treatment with morphine sulfate extended-release was initiated without a washout period from prior medication. The initial morphine sulfate extended-release dose was tailored to the patient (per morphine sulfate extended-release conversion tables and investigator discretion). ${ }^{15}$ In general, the starting dose was to be $30 \mathrm{mg}$ once daily for opioid-naïve patients. Opioid-experienced patients were to be initiated on an equivalent daily dose of morphine sulfate extended-release given once daily and instructed to destroy any remaining prior medication. The investigator was allowed to adjust the dose throughout the study to achieve a stable dose, defined as a dose that provided a pain score $<4$ on the numerical rating scale, required up to two doses of rescue medication daily, and provided a level of side effects deemed acceptable by patients and investigators. Determination of a stable dose was made at the discretion of the investigator. Patients were provided with a debit card for prescription medication to present to a pharmacy to receive study drugs free of charge. The card also allowed the investigator to obtain information about the date and location where the prescription was filled and the number of pills dispensed. The prescription card was reinitialized at visits 2 to 4 .

Ibuprofen $200 \mathrm{mg}$ (not to exceed $1200 \mathrm{mg} /$ day unless directed by the prescriber) or acetaminophen $500 \mathrm{mg}$ (not to exceed $4 \mathrm{~g} /$ day) could be taken as rescue medication; aspirin $\leq 325 \mathrm{mg}$ /day was permitted for cardiovascular prophylaxis; other analgesic medications were not permitted. Concurrent nonanalgesic medications were permitted unless they were contraindicated for use with morphine sulfate extended-release, ibuprofen, or acetaminophen. Investigators were to take appropriate steps to prevent or minimize constipation, including recommending the use of laxatives or stool softeners.

\section{Outcome measures}

Pain outcomes were measured using a patient-completed questionnaire that included components of the Brief Pain Inventory (Short Form). ${ }^{18}$ Questions included indication of any problems experienced since last visit; quantity of daily rescue medication required on average during the previous week ( 0 to $>6$ doses); rating of pain intensity (worst, least, and average) over the previous 24 hours, measured using an 11-point numerical rating scale to rate pain intensity from 0 (no pain) to 10 (pain as bad as you can imagine); how much pain relief had been achieved over the previous 24 hours from pain treatment or medications in $10 \%$ increments, from $0 \%$ (no relief) to $100 \%$ (complete relief); an indication (yes or no) whether the pain relief obtained from the current medication was enough to make a difference; and an assessment of how much pain had interfered with seven activities of daily living (general activity, mood, walking ability, normal work, relationships with other people, sleep, and enjoyment of life) during the previous 24 hours using an 11-point numerical rating scale from 0 (does not interfere) to 10 (completely interferes). The scores assessed at visits 2-5 were used to guide investigator decisions about patient pain management at each visit.

At baseline, the investigator determined each patient's level of risk for misuse and abuse using scores obtained from the Screener and Opioid Assessment for Patients with Pain-Revised $\left(\mathrm{SOAPP}^{\circledR}\right.$-R) questionnaire. ${ }^{19}$ Risk levels were then further adjusted by increasing the level if aberrant results were detected on urine drug screening and/or aberrant drug behaviors were observed, including purposeful oversedation, frequent requests for early prescription renewals, increased dose without authorization, reports of lost or stolen prescriptions, or abuse of alcohol or illicit drugs. Patients considered to be at low risk for opioid misuse and abuse were treated with morphine sulfate extended-release and monitored; those at moderate risk were treated, provided with additional counseling and reminders of their treatment agreements and responsibilities, and monitored; and those considered at high risk were to be withdrawn from the study and potentially referred to a pain specialist and/or addictionologist.

At visit 5, ie, the end-of-study visit, all patients, including those who withdrew from the study, returned to the clinic for a final evaluation of pain and activity level, adverse events, and signs of aberrant behavior using the universal precautions approach. Patients who withdrew completed this visit at the time of withdrawal if they were at the study center at the time of withdrawal; if they withdrew between visits, they returned to the study center to complete this visit. Patients and investigators evaluated therapeutic response satisfaction with treatment using patient-completed Patient Global Assessment and investigator-completed Clinician Global Assessment tools for each patient. The Patient Global 
Assessment allowed the patient to compare morphine sulfate extended-release with his or her usual pain medication in the following four areas: pain relief during the whole day, ability to perform daily activities, ability to sleep, and side effects using a five-point rating scale (much better, better, same, worse, much worse); and to rate their satisfaction with the medication and investigator use of universal precautions tools employed in the study using a five-point rating scale (very satisfied, satisfied, neutral, dissatisfied, very dissatisfied). Investigators used a five-point scale on the Clinician Global Assessment tool to rate their satisfaction with study medication, level of improvement, and level of utility of the universal precautions intervention regimen (very satisfied, satisfied, neutral, dissatisfied, very dissatisfied). Safety assessments included vital signs, physical examination, and adverse events, which were categorized according to the Medical Dictionary for Regulatory Activities.

\section{Analysis populations and withdrawal from study}

For this study, the safety population included all patients who enrolled and filled a prescription for morphine sulfate extended-release. The intent-to-treat population included all patients with at least one completed visit in the treatment part of the study. The completer population included those patients who completed all treatment visits.

Patients could be withdrawn from the study at any time for reasons including, but not limited to: pregnancy, patient choice, investigator discretion (eg, occurrence of a serious adverse event, changes in patient condition that rendered study participation unacceptable), sponsor termination (eg, noncompliance, administrative reasons), assignment to high-risk level for misuse/abuse of prohibited drugs, or illegal activity involving morphine sulfate extended-release. Patients who had withdrawn from the study were asked to provide a reason for discontinuation, which was recorded by the investigator; more than one reason could be given.

\section{Statistical analysis}

In this exploratory study, a sample size of 2000 patients from up to 600 centers was planned to provide $90 \%$ power to detect a change from baseline that was at least $7 \%$ of the standard deviation (SD) of the change score (one-sample $t$-test, significance level of $5 \%$, two-sided). Due to later time constraints, 1612 patients were screened.

Analyses were based on all available data for the safety and completer populations. The investigator was to record all patient data and provide a documented explanation for any missing data. Descriptive statistics were used to report continuous variables, categorical variables, between subgroup comparisons, and changes from baseline. A paired $t$-test was used to compare changes from baseline in average pain scores in the last 24 hours at each visit and changes from baseline in pain relief at each visit. The primary outcome was the change from baseline in average pain score at each study visit. Secondary outcomes included change from baseline in the other pain scores, as well as change in pain interference with activities of daily living. Analyses were based on all available data at a time point. No imputation methods were employed. No multiple comparison adjustments were made for this exploratory study. Summaries of all available data were presented.

\section{Results \\ Disposition, demographics, and baseline scores}

A total of 286 primary care centers entered into the study and 281 (with 281 investigators) contributed data. The investigators were from 34 states in the United States and from Puerto Rico. Of 1612 patients screened, 1570 (97\%) were enrolled, 1487 $(92 \%)$ were enrolled and used the prescription card at least once (safety population), and 561 (561/1487; 38\%) completed the study. There were 890 patients who withdrew during the course of the study and for whom a reason was recorded; the most common reasons for discontinuation (more than one could be provided) among these patients were patient choice $(53 \%)$, adverse events $(34 \%)$, and treatment failure (12\%). Most patients who discontinued due to patient choice also had other reasons identified, most commonly adverse events (28\%), treatment failure (16\%), and investigator's decision (4\%). Patients rated as having a high risk level of misuse and abuse were required to be withdrawn from the study and accounted for $5 \%$ of discontinuations.

Results are reported based on all nonmissing data. Demographics and baseline characteristics of the safety population are shown in Table 1 . The safety population was primarily female $(57 \%)$, white $(87 \%)$, and had chronic pain for more than one year (92\%). Median age was 52 years (range 21-92 years). At baseline, 79\% of patients were taking an opioid. The most common pain category, reported by $70 \%$ of patients, was musculoskeletal. The most common location of pain was the back $(73 \%)$. Few patients indicated that they had a history of illicit drug use $(5 \%)$ or had participated in a 12 -step drug treatment program $(2 \%)$. At baseline, mean $( \pm \mathrm{SD})$ pain intensity scores were $6.2 \pm 2.3$ for average pain in the last 24 hours, $7.8 \pm 2.5$ for worst pain in the last 24 hours, and $4.7 \pm 2.7$ for least pain in the last 24 hours. 
Table I Demographics and baseline characteristics

\begin{tabular}{|c|c|c|}
\hline \multirow[t]{2}{*}{ Characteristic } & \multicolumn{2}{|c|}{$\begin{array}{l}\text { Safety population } \\
n=1487\end{array}$} \\
\hline & $\mathbf{n}$ & \\
\hline Age (years) & 1470 & \\
\hline Mean (SD) & & $52.7(13.62)$ \\
\hline Median & & 52.0 \\
\hline Range (minimum-maximum) & & $21-92$ \\
\hline Gender, n (\%) & 1469 & \\
\hline Men & & $630(43)$ \\
\hline Women & & $839(57)$ \\
\hline Race, n (\%) & 1434 & \\
\hline White & & $1240(87)$ \\
\hline Black & & $124(9)$ \\
\hline Hispanic & & $55(4)$ \\
\hline Asian & & $4(0.3)$ \\
\hline Other & & $I 1(I)$ \\
\hline Duration of current pain, $\mathrm{n}(\%)$ & 1458 & \\
\hline $3-12$ months & & $120(8)$ \\
\hline$>$ I year & & $1338(92)$ \\
\hline \multicolumn{3}{|l|}{ Pain category, ${ }^{\mathrm{a}} \mathrm{n}(\%)$} \\
\hline Musculoskeletal & 1437 & $999(70)$ \\
\hline Osteoarthritis & 1436 & $349(24)$ \\
\hline Nerve-related & 1437 & $330(23)$ \\
\hline Cancer-related & 1436 & $12(0.8)$ \\
\hline Other & 1436 & $154(\mathrm{II})$ \\
\hline \multicolumn{3}{|l|}{ Pain location, ${ }^{\mathrm{a}} \mathrm{n}(\%)$} \\
\hline Back & 1467 & $1076(73)$ \\
\hline Limbs & 1467 & $632(43)$ \\
\hline Face/head/neck & 1466 & $245(17)$ \\
\hline Torso & 1466 & $117(8)$ \\
\hline Other & 1466 & $201(14)$ \\
\hline \multicolumn{3}{|l|}{ Pain score, mean (SD) } \\
\hline Average pain & 1474 & $6.2(2.3)$ \\
\hline Worst pain & 1475 & $7.8(2.5)$ \\
\hline Least pain & 1475 & $4.7(2.7)$ \\
\hline \multicolumn{3}{|c|}{ Concurrent medical conditions, $\mathrm{n}(\%)$} \\
\hline Depression & 1480 & $622(42)$ \\
\hline Anxiety/panic disorder & 1480 & $436(30)$ \\
\hline Diabetes mellitus & 1480 & $287(19)$ \\
\hline Chronic constipation & 1480 & $148(10)$ \\
\hline History of cancer & 1480 & $79(5)$ \\
\hline Benign prostatic hypertrophy & 1480 & $44(3)$ \\
\hline Nausea & 1480 & $30(2)$ \\
\hline Other & 1480 & $624(42)$ \\
\hline $\begin{array}{l}\text { Participation in } 12 \text {-step drug } \\
\text { treatment program, } \mathrm{n}(\%)\end{array}$ & 1480 & $31(2)$ \\
\hline Illicit drug use, $n(\%)$ & 1444 & $72(5)$ \\
\hline $\begin{array}{l}\text { Opioid experience (short-acting } \\
\text { and/or long-acting), } \mathrm{n}(\%)\end{array}$ & $|48|$ & $1173(79)$ \\
\hline
\end{tabular}

Note: aPatient could choose more than one category for etiology, location.

Abbreviation: SD, standard deviation.

\section{Effectiveness of morphine sulfate extended-release}

Figure 2 shows the daily doses of morphine sulfate extendedrelease prescribed at each of the study visits. Total daily doses ranged from 30 to $1440 \mathrm{mg}$. During visits $1-4$ most ( $\geq 83 \%$ ) patients received a total daily dose of $30-120 \mathrm{mg} ; \leq 17 \%$ patients received a total daily dose of $\geq 150 \mathrm{mg}$ and $\leq 8 \%$ received a total daily dose of $\geq 240 \mathrm{mg}$.

Pain intensity scores were reduced from the baseline value at each visit $(P<0.0001$ for all visits). In the safety population, the mean $( \pm \mathrm{SD})$ change from baseline in average pain intensity in the last 24 hours (baseline $6.2 \pm 2.3$ ) at each visit was: visit $2(-0.8 \pm 2.2)$, visit $3(-1.6 \pm 2.3)$, and visit $4(-1.7 \pm 2.2$, Figure $3 \mathrm{~A})$. At visit 5 , which included scores from patients who had discontinued from the study as well as completed patients, the change from baseline was $-1.1 \pm 2.4$. Similar trends were observed for pain at its worst and least in the last 24 hours at each visit. When patients were asked to report percent pain relief, mean values ranged from $46.1 \%$ to $55.4 \%$ at each visit $(P<0.0001$ at visits 3 and 4 ; not significant at visit 2 and at visit 5 , which included those patients who had discontinued).

Patients experienced reductions in interference with activities of daily living scores, particularly in the general activity, normal work, sleep, enjoyment of life, and walking ability categories; smaller effects were seen in mood and relationships with other people (Figure 4A and B). In response to the question "Is the amount of pain relief you are now obtaining from your current pain reliever (morphine sulfate extended-release) enough to make a difference?", increasing percentages of the safety population between visits 2 and 4 (51.2\% at visit 2, 77.3\% at visit 3, and 79.4\% at visit 4) replied in the affirmative.

Average daily use of rescue medication was 1-4 pills for most $(60 \%-70 \%)$ patients at each visit. The percentage of patients using more than six pills ranged from $7.3 \%$ to $10.5 \%$ across visits. The percentage of patients who had taken acetaminophen ranged from $40 \%$ to $47 \%$. Percent use of ibuprofen ranged from $37 \%$ to $42 \%$.

Effectiveness data were also evaluated for patients in the completer population. In this population, scores for mean $( \pm \mathrm{SD})$ pain intensity on average also decreased from baseline (average pain in the last 24 hours $6.1 \pm 1.7$ ) at each subsequent visit, but the mean decrease from baseline in scores for average pain intensity in the last 24 hours was maintained through visit 5 and not increased from visit 4 , as in the safety population (Figure $3 \mathrm{~B})$. Mean $( \pm \mathrm{SD})$ decreases from baseline in average pain intensity scores in the last 24 hours in the completer population were $-0.9 \pm 2.1$ at visit $2,-1.7 \pm 2.2$ at visit $3,-1.8 \pm 2.2$ at visit 4 , and $-1.7 \pm 2.3$ at visit 5 . Similar trends were observed for pain at its worst and least in the last 24 hours at each visit after baseline in the completer population (Figure 3B). For the completer 


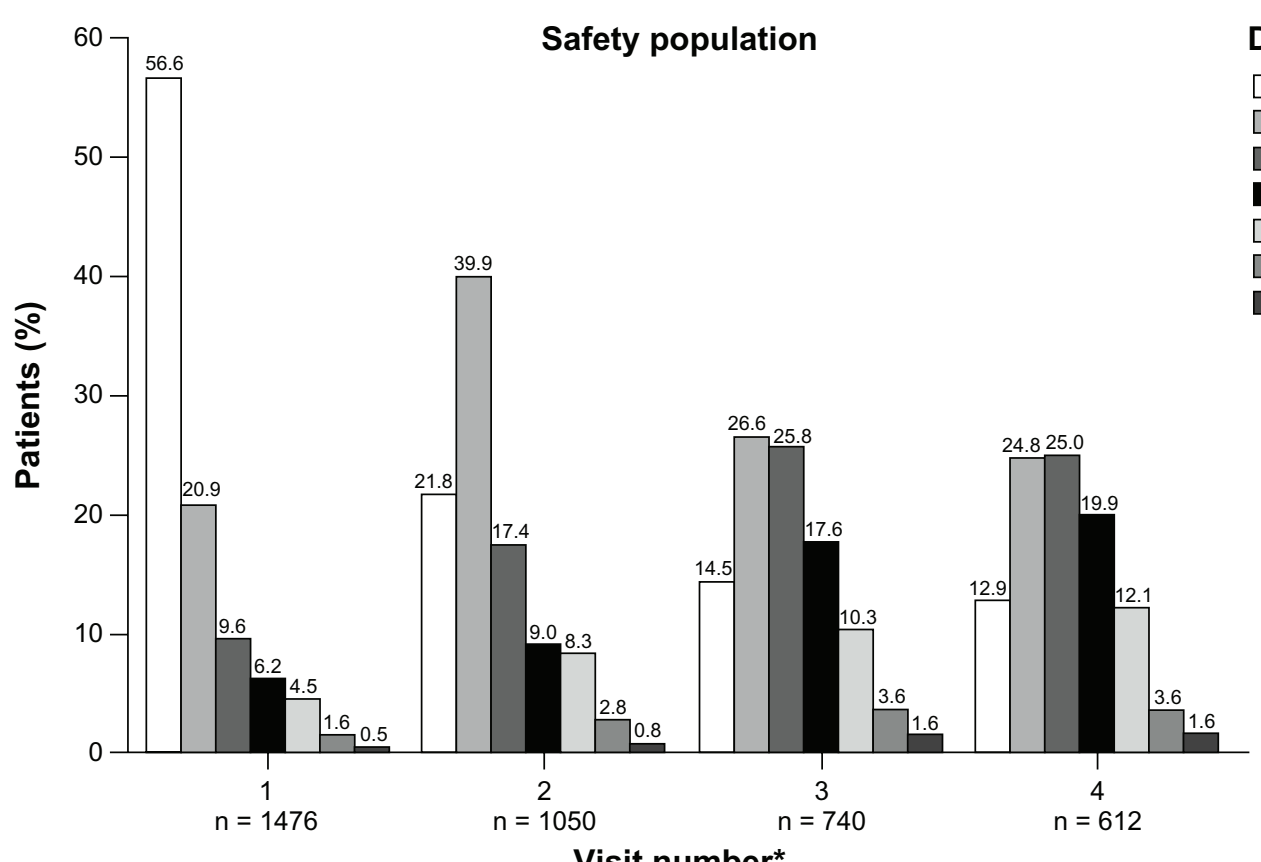

Visit number*

Daily dose (mg)

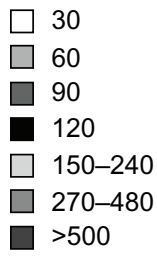

Figure 2 Daily doses of morphine sulfate extended-release across study visits in safety population.

Note: *Values for $\mathrm{n}$ based on available data.

population, mean patient-reported percent relief ranged from $47 \%$ to $57 \%$. Reductions in pain interference with activities of daily living were observed for all functions examined in the completer population (Figure 4B).

\section{Global assessments at visit 5}

In-clinic Patient Global Assessment values at visit 5 are shown in Table 2. Of patients in the safety population, $89 \%$ indicated that they were satisfied or very satisfied with the investigator's use of universal precautions tools ( $8 \%$, neutral; $2 \%$, dissatisfied or very dissatisfied), and $51 \%$ indicated they were satisfied or very satisfied with their morphine sulfate extended-release treatment (18\%, neutral; 30\%, dissatisfied or very dissatisfied). Pain relief during the whole day was rated as better or much better by $56 \%$ (23\%, same; $21 \%$, worse or much worse); ability to perform daily activities by $45 \%$ (31\%, same; $24 \%$, worse or much worse); sleep by $40 \%$ (40\%, same; $20 \%$, worse or much worse); and side effects by $30 \%$ of patients in the safety population $(29 \%$, same; $41 \%$, worse or much worse).

Of the completer population, 95\% indicated they were satisfied or very satisfied with the investigator's use of universal precautions tools $(5 \%$, neutral; $<1 \%$ dissatisfied or very dissatisfied), and $81 \%$ indicated they were satisfied or very satisfied with their morphine sulfate extended-release treatment (14\%, neutral; 5\%, dissatisfied or very dissatisfied, Table 2). Pain relief during the whole day was rated as better or much better by $78 \%$ ( $15 \%$, same; $6 \%$, worse or much worse); ability to perform daily activities by $68 \%(26 \%$, neutral; $7 \%$, worse or much worse); sleep by $52 \%(40 \%$, same; $8 \%$, worse or much worse); and side effects by $51 \%$ of patients (35\%, same; $14 \%$, worse or much worse) in the completer population.

Using the Clinician Global Assessment, investigators reported being satisfied or very satisfied with the use of morphine sulfate extended-release for management of moderate-to-severe pain in $63 \%$ of patients in the safety population $(19 \%$, neutral; $18 \%$, dissatisfied or very dissatisfied) and were satisfied or very satisfied with the level of improvement in chronic pain control in $63 \%$ of patients in the safety population (18\%, neutral; 19\%, dissatisfied or very dissatisfied, Table 3). In addition, investigators were satisfied or very satisfied with the utility of the universal precautions program in $75 \%$ of patients ( $21 \%$, neutral; $4 \%$, dissatisfied or very dissatisfied) in the safety population.

Investigators reported being satisfied or very satisfied with morphine sulfate extended-release use for management of moderate-to-severe pain in $91 \%$ of completed patients $(6 \%$, neutral; 3\%, dissatisfied or very dissatisfied). Investigators were also satisfied or very satisfied with the improvement of chronic pain control in $90 \%$ of completed patients $(7 \%$, neutral; $3 \%$, dissatisfied or very dissatisfied) and with the utility of the universal precautions program for $87 \%$ of the 


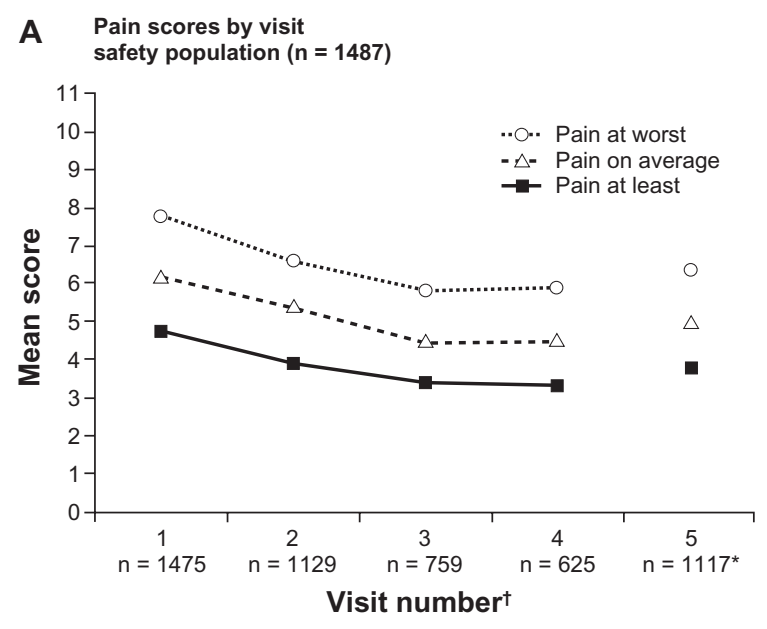

B Pain scores by visit completer population $(n=561)$

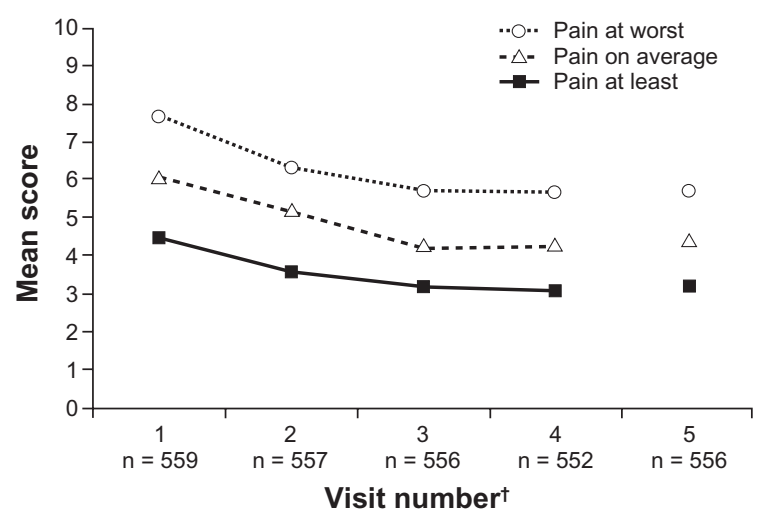

Figure 3 Pain intensity scores in the last 24 hours by study visit in the safety (A) and completer (B) populations.

Notes: "Includes all patients including those who had discontinued from the study and were no longer taking study medication; ${ }^{\dagger}$ values for $\mathrm{n}$ based on available data.

completed patients $(12 \%$, neutral; $1 \%$, dissatisfied or very dissatisfied, Table 3).

\section{Safety}

Nearly half (48\%) of the patients in the safety population experienced at least one adverse event. The most common adverse events reported were constipation (14\%), nausea (11\%), vomiting (5\%), and somnolence (5\%, see Table 4). Adverse events were identified as one reason for withdrawal from the study in $21 \%$ of the safety population; an additional $7 \%$ of patients reported adverse events leading to withdrawal of study medication on the adverse event case report forms. The most common adverse events ( $\geq 1 \%$ ) resulting in withdrawal from the study were nausea $(8 \%$; $\mathrm{n}=114)$, constipation $(5 \% ; \mathrm{n}=77)$, vomiting $(4 \% ; \mathrm{n}=53)$, somnolence $(3 \% ; n=40)$, fatigue $(2 \% ; n=35)$, headache
$(2 \% ; n=32)$, dizziness $(2 \% ; n=31)$, pruritus $(2 \% ; n=26)$, and abdominal pain $(1 \% ; n=18)$. Sixty patients $(4 \%)$ in the safety population reported serious treatment-emergent adverse events, two of which (nausea) were considered treatment-related. The most common serious adverse events were pneumonia $(n=8)$, congestive cardiac failure $(n=4)$, gastrointestinal hemorrhage $(n=4)$, nausea $(n=4)$, hypoglycemia $(n=4)$, and acute renal failure $(n=5)$.

Ten deaths $(0.7 \%)$ occurred during the study. Most were due to concomitant medical conditions and none were considered by the investigators to be attributable to the study drug. One death occurred in a 46-year-old man with significant diabetes and hypertension whose concomitant medications included metformin, glipizide, citalopram, and diazepam. At enrollment this patient indicated hydrocodone, nonsteroidal anti-inflammatory drugs, and tramadol as concurrent medications. The patient did not have a history of opioid abuse or recreational drug use. The starting dose of morphine sulfate extended-release was $240 \mathrm{mg} /$ day. The coroner ruled that the death, which occurred five days after enrollment, was accidental secondary to the use of opiate, citalopram, and diazepam. In the investigator's opinion, the death was not reasonably attributed to the study drug; however, the death was judged by the sponsor as reasonably attributable to the study drug.

\section{Universal precautions}

Most patients in the safety population (52\%) were identified as being at moderate risk for opioid misuse and abuse at baseline, while $47 \%$ were assigned a low risk level, and $1 \%$ were assigned a high-risk level. On urine drug screen at baseline, $14 \%$ of patients were reported as positive for marijuana and $10 \%$ were reported as positive for cocaine. Positive urine drug screen results were also reported for other illicit drugs, such as phencyclidine and 3,4-methylenedioxymethamphetamine, each in $6 \%$ of patients. Positive urine drug screen results for illicit drugs were reported throughout all study visits. More detail regarding risks and incidence of misuse and abuse and levels of compliance will be reported in a separate paper. ${ }^{20}$

\section{Discussion}

In this population of primary care patients with chronic, moderate-to-severe pain, in a study assessing a universal precautions approach to determine risk level for opioid misuse and abuse and provide appropriate management, patients receiving morphine sulfate extended-release experienced measurable improvement in pain control as measured 

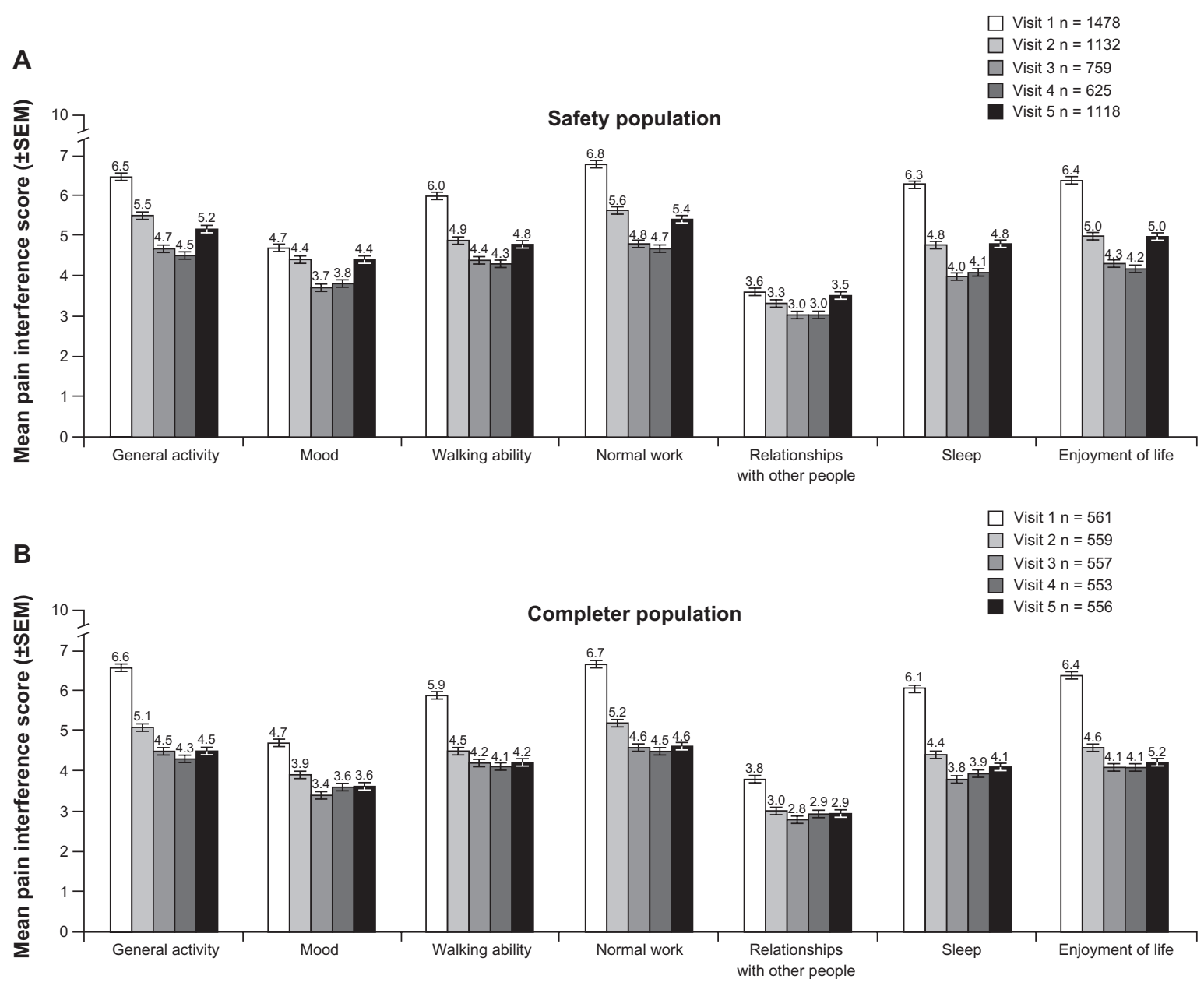

Figure 4 Pain interference with activities of daily living by study visit in safety $(\mathbf{A})$ and completer (B) populations.

Notes: $0=$ does not interfere, $10=$ completeley interferes; values for $\mathrm{n}$ based on available data. SEM, standard error of measurement.

by reduced pain intensity scores in both the safety and completer populations. Pain scores fell until visit 3 when the dose of morphine sulfate extended-release was stabilized. Patients in both the safety and completer populations also experienced reduced interference of pain in activities of daily living, in all functions and activities evaluated. Fifty-one percent of patients in the safety population and $81 \%$ in the completer population reported being satisfied or very satisfied with morphine sulfate extended-release treatment.

In the current study, a statistical improvement in pain scores was observed. However, it did not reach the two-point criteria for a clinically important difference based on analyses of other studies in patients with various types of chronic pain $^{21,22}$ or other studies using the same morphine sulfate extended-release formulation and a similar pain intensity scale. ${ }^{23,24}$ This is likely due to differences in methodology. In the current study, patients entered the trial on their pain medications without washout from previous analgesics and were not titrated to a prespecified pain intensity level before effectiveness was evaluated. They could also have been experiencing adequate relief but unsatisfactory side effects at baseline, thus limiting the potential reduction in pain scores. It was noted that patient-reported percent pain relief was numerically higher than that calculated based on decrease in pain intensity scores $(46.1 \%$ to $55.4 \%$ pain relief reported by patients versus $27 \%$ calculated using pain intensity scores). The reason(s) for this difference is (are) unclear, but may include differences in patient interpretation of the scales, overestimation of pain scores, or inclusion of other considerations, such as quality of life or physical function, in assessing percent relief. Importantly, $81 \%$ of patients who completed the study reported being satisfied or very satisfied with treatment (as did $51 \%$ of all patients, including noncompleters), and by visits 3 and $4,77 \%$ and $79 \%$ of patients, respectively, reported that pain relief was enough to make a difference. Results suggest that assessment 
Table 2 Patient global assessment at visit 5

\begin{tabular}{|c|c|c|c|c|}
\hline \multirow[t]{2}{*}{ n (\%) } & \multicolumn{2}{|c|}{$\begin{array}{l}\text { Safety population } \\
n=1487\end{array}$} & \multicolumn{2}{|c|}{$\begin{array}{l}\text { Completer population } \\
\mathrm{n}=56 \mathrm{I}\end{array}$} \\
\hline & Much better & Better & Much better & Better \\
\hline $\begin{array}{l}\text { Pain relief during the whole day ( } 24 \text { hours), } \\
\text { safety } n=I \mid I 3 \text {; completer } n=556\end{array}$ & $260(23)$ & $358(32)$ & $193(35)$ & $24 I(43)$ \\
\hline $\begin{array}{l}\text { Ability to perform daily activities, } \\
\text { safety } n=1110 \text {; completer } n=555\end{array}$ & $174(16)$ & $325(29)$ & $139(25)$ & $236(43)$ \\
\hline $\begin{array}{l}\text { Ability to sleep, } \\
\text { safety } n=1110 \text {; completer } n=556\end{array}$ & $154(14)$ & $292(26)$ & $98(18)$ & I91 (34) \\
\hline \multirow[t]{2}{*}{$\begin{array}{l}\text { Side effects } \\
\qquad \text { safety } n=1085, \text { completer } n=537\end{array}$} & $138(13)$ & $189(17)$ & 118 (22) & 155 (29) \\
\hline & Very satisfied & Satisfied & Very satisfied & Satisfied \\
\hline $\begin{array}{l}\text { Satisfaction with morphine sulfate extended-release, } \\
\text { safety } n=1119 ; \text { completer } n=557\end{array}$ & $299(27)$ & $275(25)$ & $252(45)$ & $197(35)$ \\
\hline $\begin{array}{l}\text { Satisfaction with doctor's use of treatment agreement, } \\
\text { pill counts, questionnaires in pain management, } \\
\text { safety } n=\text { I I 22; completer } n=558\end{array}$ & $724(65)$ & $277(25)$ & $4 \mid 4(74)$ & II $5(2 \mathrm{I})$ \\
\hline
\end{tabular}

of treatment success in future trials and in the clinical setting should include a focus on functional improvement.

The withdrawal rate in this study was $62 \%$; the most common reasons (more than one could be provided) were patient choice, adverse events, and treatment failure. The overall rates appear toward the higher range of discontinuation rates of $38 \%-63 \%$ observed in other studies using opioid therapy over a 2-6-month period for management of chronic, moderateto-severe pain, ${ }^{16,23,25-28}$ possibly due to the amount and types of monitoring required of patients. The discontinuation rates due to adverse events and treatment failure were similar to those reported in other studies. ${ }^{16,23,25-28}$ Unlike other studies, this study required that patients identified at high risk for opioid abuse be withdrawn. Although a small percentage $(5 \%)$, this did contribute to the withdrawal rate observed. Other possible explanations for the high rate of withdrawal from the study included enrollment of sites that had not previously participated in a research study, patients with fear of exposure about misuse/abuse of illicit/nonprescribed drugs or who did not wish to be monitored for aberrant drug behavior, or patients who felt worse on morphine sulfate extended-release than while not taking the medication. While most patients reported being satisfied with investigator use of the universal precautions tools, it is possible that because this assessment was conducted during clinic visits, patients may not have been fully candid during their assessments. Nonetheless, the withdrawal rate observed in this study did not appear to affect assessments of the effectiveness of morphine sulfate extended-release because statistically significant improvements on pain intensity scores were seen in both the safety population as well as the completers.

As with any open-label study, the design of the study limits generalization of the conclusions. It was not possible to exclude bias. Further, although the intention was to provide a broad sampling of patients and investigators across the United States, patient demographics and investigator selection may not be representative of a "real-world" population. The recruitment of investigators who had experience in prescribing opioids may have yielded a higher proportion of patients who had previously used opioids.

Study entry criteria were based on the presence of chronic, moderate-to-severe pain. Most patients were reported to have

Table 3 Clinician global assessment at visit 5

\begin{tabular}{|c|c|c|c|c|}
\hline \multirow[t]{2}{*}{ n (\%) } & \multicolumn{2}{|c|}{$\begin{array}{l}\text { Safety population } \\
n=1487\end{array}$} & \multicolumn{2}{|c|}{$\begin{array}{l}\text { Completer population } \\
n=56 \mathrm{I}\end{array}$} \\
\hline & Very satisfied & Satisfied & Very satisfied & Satisfied \\
\hline $\begin{array}{l}\text { Treating moderate-to-severe pain, } \\
\text { safety } n=1343 \text {; completer } n=558\end{array}$ & $319(24)$ & $530(40)$ & $245(44)$ & $265(48)$ \\
\hline $\begin{array}{l}\text { Improvement in chronic pain, } \\
\text { safety } n=1342 \text {; completer } n=558\end{array}$ & $304(23)$ & $536(40)$ & $235(42)$ & $269(48)$ \\
\hline $\begin{array}{l}\text { Utility of risk assessment program, } \\
\text { safety } n=1344 \text {; completer } n=558\end{array}$ & $366(27)$ & $644(48)$ & $23 I(4 I)$ & $254(46)$ \\
\hline
\end{tabular}


Table 4 Patients with treatment-emergent adverse events $\geq 1 \%$ of population

\begin{tabular}{ll}
\hline Event, $\mathbf{n}(\%)$ & $\begin{array}{l}\text { Patients } \\
\text { (safety population) } \\
\mathbf{n}=1 \mathbf{4 8 7}\end{array}$ \\
\hline Constipation & $206(14)$ \\
Nausea & $166(1)$ \\
Vomiting & $81(5)$ \\
Somnolence & $79(5)$ \\
Dizziness & $52(4)$ \\
Fatigue & $52(4)$ \\
Headache & $47(3)$ \\
Pruritus & $45(3)$ \\
Diarrhea & $27(2)$ \\
Abdominal pain & $24(2)$ \\
Insomnia & $22(2)$ \\
Pain & $19(1)$ \\
Dry mouth & $18(1)$ \\
Hyperhidrosis & $18(1)$ \\
Rash & $18(1)$ \\
Sedation & $15(1)$ \\
\hline
\end{tabular}

musculoskeletal, osteoarthritic, and/or neuropathic pain, although the study protocol did not include a specific workup to establish a differential diagnosis. As in clinical practice, patients were allowed to continue taking other medications, unless they were primarily indicated for analgesia. Given that a substantial proportion of patients also had depression and/ or anxiety during the study, it is possible that some of the medications they were taking for these conditions functioned as adjunctive analgesics, impacting the results. While having the potential to impact the study results, this limitation might more closely represent the situation in a real-world population of patients on a variety of medications.

The current study is the first large-scale study to assess the utility of the universal precautions approach, including risk assessment and stratification, as well as the use of morphine sulfate extended-release in the primary care setting. Future studies can build upon the knowledge by including a means of identifying how investigators make treatment and risk assessment decisions using the available information, and how these decisions impact patient outcomes.

\section{Conclusion}

In this primary care population of patients with chronic, moderate-to-severe pain, using a universal precautions approach to pain management and treatment with morphine sulfate extended-release, patients experienced decreased pain intensity scores (average, least, and worst) and reduced pain interference with activities of daily living from baseline values. The most common adverse events were those commonly seen with opioid therapy, ie, constipation, nausea, vomiting, and somnolence. Most investigators and patients were satisfied or very satisfied with the use of morphine sulfate extendedrelease for treatment of moderate-to-severe pain and the level of improvement in pain control attained with this therapy.

While pain relief was achieved in this study, the proportion of patients rated at moderate or greater risk for opioid misuse and abuse and the identification of illicit drug use suggest a need for continuous patient monitoring. Further education of primary care providers, and development of better strategies to aid in the identification of patients with chronic pain receiving long-term opioid therapy who may be at risk for drug misuse and abuse, may also be warranted.

\section{Acknowledgments}

The authors gratefully acknowledge the scientific contributions of Sherry Siegel and Nathaniel Katz to the study design and manuscript, Rick Slattery and the team at Clinical Marketing Consortium, Christopher Neumann, Michael Toscani, and the team at KOL, and Philip D'Alessandro and the team at YNF for coordinating the execution of the trial, Mavis Waller and the team at REGISTRAT ${ }^{\circledR}$-MAPI Inc for carrying out the trial, including monitoring of sites and collection of study data, and Inflexxion Inc for use of the SOAPP-R.

\section{Disclosure}

JB was an investigator on the trial presented here and has previously received honoraria from Abbott, AstraZeneca, Daiichi Sankyo, Forest Laboratories, GlaxoSmithKline, Novartis, and Pfizer Inc. L Webster has performed research, acted as a consultant, and served on an advisory board for King Pharmaceuticals ${ }^{\circledR}$ Inc. In addition, L Webster has performed research for Adolor Corporation, Alkermes Inc, Allergan Inc, Astellas Pharma, AstraZeneca, Bayer HealthCare, BioDelivery Sciences International, Boston Scientific, Cephalon Inc, Collegium Pharmaceutical, Covidien, Eisai Co, Ltd, Elan Corporation, Gilead Sciences, GlaxoSmithKline, Meagan Medical, Medtronic, Nektar Therapeutics, NeurogesX Inc, Shionogi USA Inc, St Renatus LLC, Sucampo Pharma Americas, Teva Pharmaceuticals, Theravance Inc, Vertex Pharmaceuticals, and Xanodyne Pharmaceuticals, and has acted as a consultant, received honoraria, and served on an advisory board for the American Board of Pain Medicine, AstraZeneca, BioDelivery Sciences International, Boston Scientific, Cephalon Inc, Covidien Mallinckrodt, Janssen Pharmaceutical KK, Nevro Corporation, PharmacoFore Inc, Purdue Pharma, and Theravance Inc. KL was an investigator on this trial for King Pharmaceuticals Inc. BS, CLR, and JMC are current employees 
of Pfizer Inc and former employees of King Pharmaceuticals Inc, and hold stock and/or stock options in the company. L Wase is a former employee of King Pharmaceuticals Inc and holds stock and/or stock options in the company. This study was sponsored by King Pharmaceuticals Inc, which was acquired by Pfizer Inc in March 2011. Editorial/writing support was provided by Carol Berry and Julie Gerke of Quintiles Medical Communications, Parsippany, NJ, and was funded by King Pharmaceuticals Inc, which was acquired by Pfizer Inc in March 2011.

\section{References}

1. Kuehn BM. Opioid prescriptions soar: increase in legitimate use as well as abuse. JAMA. 2007;297:249-251.

2. Substance Abuse and Mental Health Services Administration. Results from the 2008 National Survey on Drug Use and Health: National Findings (Office of Applied Studies, NSDUH Series H-36, HHS Publication No SMA 09-4434). Rockville, MD; 2009. Available at: http://www.oas.samhsa.gov/nsduh/2k8nsduh/2k8results.cfm. Accessed October 2, 2009.

3. Gagnon AM, Kahan M, Srivastava A. Opioid use and abuse: is there a problem? Clin J Pain. 2007;23:661-662.

4. Chou R, Fanciullo GJ, Fine PG, et al. Opioid treatment guidelines. Clinical guidelines for the use of chronic opioid therapy in chronic noncancer pain. J Pain. 2009;10:113-130.

5. Wasan AD, Wootton J, Jamison RN. Dealing with difficult patients in your pain practice. Reg Anesth Pain Med. 2005;30:184-192.

6. Gourlay DL, Heit HA, Almahrezi A. Universal precautions in pain medicine: a rational approach to the treatment of chronic pain. Pain Med. 2005;6:107-112.

7. Passik SD, Kirsh KL. Forget the recipes: let's talk data. Pain Med. 2009;9:261-265.

8. Olsen Y, Daumit GL, Ford DE. Opioid prescriptions by US primary care physicians from 1992 to 2001. J Pain. 2006;7:225-235.

9. Katz NP, Adams EH, Benneyan JC, et al. Foundations of opioid risk management. Clin J Pain. 2007;23:103-118.

10. Ives TJ, Chelminski PR, Hammett-Stabler CA, et al. Predictors of opioid misuse in patients with chronic pain: a prospective cohort study. $B M C$ Health Serv Res. 2006;6:46.

11. Reid MC, Engles-Horton LL, Weber MB, et al. Use of opioid medications for chronic noncancer pain syndromes in primary care. J Gen Intern Med. 2002;17:173-179.

12. Wiedemer NL, Harden PS, Arndt IO, Gallagher RM. The opioid renewal clinic: a primary care, managed approach to opioid therapy in chronic pain patients at risk for substance abuse. Pain Med. 2007;8:573-584.

13. Olsen Y, Daumit GL. Opioid prescribing for chronic nonmalignant pain in primary care: challenges and solutions. Adv Psychosom Med. 2004;25:138-150.

14. King Pharmaceuticals Inc. Evaluation of Risk Minimization, Assessment and Outcomes in Patients With Chronic Pain Taking Avinza (ACCESS 2008). In: ClinicalTrials.gov [Internet]. Bethesda (MD): National Library of Medicine (US). 2000- [April 26, 2010]. Available from: http://clinicaltrials.gov/ct2/show/NCT00640042 NLM Identifier: NCT00640042. Accessed December 8, 2010.

Journal of Pain Research

\section{Publish your work in this journal}

The Journal of Pain Research is an international, peer-reviewed, open access, online journal that welcomes laboratory and clinical findings in the fields of pain research and the prevention and management of pain. Original research, reviews, symposium reports, hypothesis formation and commentaries are all considered for publication.

Submit your manuscript here: http://www.dovepress.com/journal-of-pain-research-journal
15. Avinza [package insert]. Bristol, TN: King Pharmaceuticals Inc; April 2008.

16. Caldwell JR, Rapoport RJ, Davis JC, et al. Efficacy and safety of a once-daily morphine formulation in chronic, moderate-to-severe osteoarthritis pain: results from a randomized, placebo-controlled, double-blind trial and an open-label extension trial. J Pain Symptom Manage. 2002;23:278-291.

17. Portenoy RK, Sciberras A, Eliot L, et al. Steady-state pharmacokinetic comparison of a new, extended-release, once-daily morphine formulation, Avinza, and a twice-daily controlled-release morphine formulation in patients with chronic moderate-to-severe pain. J Pain Symptom Manage. 2002;23:292-300.

18. Cleeland CS, Ryan KM. Pain assessment: global use of the Brief Pain Inventory. Ann Acad Med Singapore. 1994;23:129-138.

19. Butler SF, Fernandez K, Benoit C, Budman SH, Jamison RN. Validation of the revised Screener and Opioid Assessment for Patients with Pain (SOAPP-R). J Pain. 2008;9:360-372.

20. Brown J, Setnik B, Lee K, et al. Assessment, stratification, and monitoring of the risk for prescription opioid misuse and abuse in the primary care setting. J Opioid Manag. In press.

21. Farrar JT, Young JP Jr, LaMoreaux L, Werth JL, Poole RM. Clinical importance of changes in chronic pain intensity measured on an 11-point numerical pain rating scale. Pain. 2001;94:149-158.

22. Farrar JT, Pritchett YL, Robinson M, Prakash A, Chappell A. The clinical importance of changes in the 0-10 numeric rating scale for worst, least, and average pain intensity: analysis of data from clinical trials of duloxetine in pain disorders. J Pain. 2010;11:109-118.

23. Rauck R, Bookbinder S, Bunker T, et al. The ACTION study: a randomized, open label, multicenter trial comparing once-a-day extended-release morphine sulfate capsules (Avinza) to twice-a-day controlled-release oxycodone hydrochloride tablets (OxyContin) for the treatment of chronic, moderate to severe low back pain. J Opioid Manage. 2006;2:155-166.

24. Adams EH, Chwiecko P, Ace-Wagoner Y, et al. A study of Avinza (morphine sulfate extended-release capsules) for chronic moderateto-severe noncancer pain conducted under real-world treatment conditions - the ACCPT Study. Pain Pract. 2006;6:254-264.

25. Roth SH, Fleischmann RM, Burch FX, et al. Around-the-clock, controlled-release oxycodone therapy for osteoarthritis-related pain: placebo-controlled trial and long-term evaluation. Arch Intern Med. 2000;160:853-860.

26. Nicholson B, Ross E, Sasaki J, Weil A. Randomized trial comparing polymer-coated extended-release morphine sulfate to controlled-release oxycodone $\mathrm{HCl}$ in moderate to severe nonmalignant pain. Curr Med Res Opin. 2006;22:1503-1514.

27. Webster LR, Butera PG, Moran LV, et al. Oxytrex minimizes physical dependence while providing effective analgesia: a randomized controlled trial in low back pain. J Pain. 2006;7:937-946.

28. Katz N, Rauck R, Ahdieh H, et al. A 12-week, randomized, placebocontrolled trial assessing the safety and efficacy of oxymorphone extended release for opioid-naive patients with chronic low back pain. Curr Med Res Opin. 2007;23:117-128.

The manuscript management system is completely online and includes a very quick and fair peer-review system, which is all easy to use. Visit http://www.dovepress.com/testimonials.php to read real quotes from published authors. 